\title{
Effect of Elevated Temperatures on a Fiber Composite Used to Strengthen Concrete Columns
}

\author{
Douglas B. Cleary,* Christopher D. CASSinO AND \\ ROSIE TORTORICE \\ Department of Civil and Environmental Engineering \\ Rowan University, 201 Mullica Hill Road \\ Glassboro, NJ 08028 \\ JAMES A. NeWEll AND BRADley W. TyReS \\ Department of Chemical Engineering \\ Rowan University, 201 Mullica Hill Road \\ Glassboro, NJ 08028
}

\begin{abstract}
Externally applied composite reinforcement can be used to provide additional strength or ductility to concrete members as part of a seismic retrofit or repair to a structure, but the composite reinforcement may be exposed to elevated temperatures. In this study, concrete cylinders were wrapped with a composite reinforcing system, exposed to a range of elevated temperatures and allowed to cool. Subsequent compression testing of the cooled cylinders indicated there was no statistically significant loss of strength until the treatment temperature was more than $30^{\circ} \mathrm{C}$ above the glass transition temperature of the epoxy. Additionally, the predominant mode of failure of the composite system changed from hoop split to seam debonding at the same temperature. This study also examined the role of a fireprotective coating that forestalled the onset of the transition of failure modes by almost $30^{\circ} \mathrm{C}$
\end{abstract}

KEY WORDS: fiber-reinforced polymer, heat, polymer, reinforced concrete, strength, thermal effects.

*Author to whom correspondence should be addressed. E-mail: cleary@rowan.edu

Journal of ReINFORCED Plastics AND COMPOSITES, Vol. 20, No. 05/2002 


\section{RESEARCH SIGNIFICANCE}

A SIGNIFICANT NUMBER of studies evaluating environmental effects such as ultraviolet light, wet-dry cycling and freeze-thaw conditions on external reinforcing systems have been published. However, there is little published work evaluating the effects of elevated temperatures. Some questions to be considered include what level of heat exposure requires replacing the system, does the mode of failure change after heating, and how effective available fire proofing systems are in preventing heat damage. This paper describes a pilot study performed to attempt to address these questions by evaluating the strength of externally reinforced tests cylinders following exposure to increasing temperature levels.

\section{BACKGROUND}

Strengthening of concrete with externally applied fiber composites is an accepted option for seismic retrofit, repair and rehabilitation of existing structures. Bridge and building components externally strengthened include columns, beams, slabs, walls, chimneys, tunnels, and silos. External reinforcing systems have been designed to increase flexural capacity or shear capacity. The additional confinement that is provided by the external reinforcing also improves compressive strengths and ductility of compression elements. Discussion of strengthening or repair of concrete structures with composites can be found in many sources. An abbreviated list of more recent sources includes Bonacci and Maalej [1], Nitereka and Neale [2], Triantafillou [3], Khalifa et al. [4], Karbhari and Howie [5], Wu and Yoshizawa [6], and ACI Committee 440 [7].

Numerous composite systems are used for strengthening. A common system produced by several different manufacturers consists of a carbon fiber or glass fiber fabric saturated with various epoxies and bonded to the concrete. The bonded fabric systems are relatively lightweight, allowing strengthening without the addition of significant dead load. The low weight also facilitates handling during installation.

External reinforcement is often intended to function as secondary reinforcing to improve structural performance during overload events of a random nature. Many of these overload events have long return periods. Therefore it is important that the external reinforcing maintains its properties for a significant lifetime. Traditional reinforcing is afforded some protection from environmental effects by the concrete that surrounds it. Even so, measures such as sealant, increased cover thickness, dense concrete, or bar coatings are often required to improve the durability of the structure. A layer of concrete does not protect external reinforcement. 
The external reinforcement may have an additional protective coating installed or may be directly exposed to the elements. Concern with the longterm durability of external reinforcing systems has led to investigations of performance under wet-dry cycling, freeze-thaw and cold temperature exposure, and ultraviolet exposure [8-12]. Despite the extensive research in these areas, the effect of elevated temperatures on composite external reinforcing systems has seen little exploration. As shown below, there is a large body of research on many environmental effects but little on the effects of elevated temperatures on common external reinforcing systems.

Toutanji and Gomez [9] simulated a harsh coastal environmental exposure by cycling small concrete beams between exposure to salt water and a $35^{\circ} \mathrm{C}, 90 \%$ humidity environment. After 300 exposure cycles the beams were tested in four point bending. The study indicated some slight degradation in ultimate load capacity after the wet-dry cycling compared to control specimens. However, because all of the tests were bond failures, the authors felt they were not conclusive regarding environmental effects on the fiber-reinforced polymer (FRP) itself.

Toutanji and Balaguru [13] found that freeze-thaw cycling was more detrimental than wet-dry cycling on the compression strength of externally reinforced cylinders loaded in compression. Toutanji and El-Korchi [14] compared the performance of glass fiber and carbon systems applied to concrete loaded in tension. They found that the glass systems were negatively affected by freeze-thaw and cycling and to greater extent, by wet-dry cycling. The carbon fiber systems were not affected. Failures with carbon systems were more brittle compared to those with glass systems.

Karbhari and Engineer [10] evaluated bonded composite plates for five environmental exposure conditions including ambient conditions, fresh water at ambient, synthetic seawater, frozen, and freeze-thaw. Concrete beams with composite plates were tested in four point bending. The authors of the study found low temperature exposure was the least important and wet-dry cycling was most detrimental to ultimate capacity of the reinforced concrete-composite system. Carbon fiber systems out performed glass fiber systems and epoxy systems with higher glass transition temperatures were preferred to those with lower glass transition temperatures because water uptake was seen to lower the glass transition temperature during environmental exposure.

ACI Committee 440 [7] identified fire or elevated temperatures as another area needing further investigation. The report specifically notes concerns the effect of fire on composite materials as well as on bond performance between concrete and the composite. Concern with elevated temperatures arises because of the types of epoxies often used in external composite systems. Because the external reinforcing must cover a large area, the use 
of heat setting epoxies is prohibitively expensive. Providing thermal blankets or other heat sources over the large areas required can be difficult and expensive. Therefore, the epoxies that bind the fabric to the concrete and provide the composite matrix are usually two-part epoxies that set at room temperature or lower. In many cases, this means the glass transition temperature of the epoxy matrix is below temperatures the materials may be exposed to during service. As the epoxies soften, there may be a temporary or permanent loss of strength either due to loss of bond in the matrix or degradation of bond between the matrix and concrete.

Gentry et al. [15] evaluated coupons of pultruded composite systems made with vinylester and polyester resins. Tests were conducted at room temperature, 50 and $80^{\circ} \mathrm{C}$. These studies were primarily intended to develop accelerated test methods and the systems studied were not wet-layup fabric systems. The coupons were tested in short beam shear and flexure. The study did find that there was a marked acceleration in property degradation between 50 and $80^{\circ} \mathrm{C}$.

Steckel et al. [11] performed a series of tests considering environmental exposures including humidity, salt water, alkali, diesel fuel, ultraviolet, and elevated temperature exposures. The effects of environmental exposures were determined from measurements of tensile properties, short beam shear strength, and hardness of the composite and from glass transition temperature. The tests were performed on 12 different reinforcing systems. The elevated temperature exposures were conducted at $60^{\circ} \mathrm{C}$. The exposure times were between 1,000 and $10,000 \mathrm{~h}$. The study found an increase in strength, likely due to improved cure of the epoxy systems. However, this study addressed long-term exposure to only somewhat elevated temperatures. It does not address shorter-term exposure to highly elevated temperatures.

Hancox [16] summarizes the work of several others related to composites exposed to high temperatures. The epoxies considered in the review required elevated temperature cures. For the systems studied exposures of $1 \mathrm{~h}$ or less at approximately $250^{\circ} \mathrm{C}$ resulted in property degradation. The systems described are not used for wet-layup installations common in rehabilitation and strengthening of large infrastructure.

Kschirsagar [12] reports an aging study of FRP wrapped concrete cylinders. It was found that $1000 \mathrm{~h}$ of immersion at elevated temperatures $\left(66^{\circ} \mathrm{C}\right)$ significantly reduced the compression strength of the system. Exposure to moisture at lower temperatures, dry heat at $66^{\circ} \mathrm{C}$, or freezethaw cycling for the same time period had no effect. After $3000 \mathrm{~h}$ of exposure, freeze-thaw cycling also began to reduce the compressive strength of the system. After $8000 \mathrm{~h}$ of exposure, cylinders exposed to all conditions except dry heat at $66^{\circ} \mathrm{C}$ had a reduced compressive strength. 
Published test result applicable to common fabric composite systems used in infrastructure strengthening have been limited to long-term exposures at temperatures up to $60^{\circ} \mathrm{C}$ and longer term (but less than 1 year) exposure at $66^{\circ} \mathrm{C}$. Short-term exposures at higher temperatures have not been published although a supplier of one common commercial system notes it has been tested to $90^{\circ} \mathrm{C}$ with no detrimental effect [17]. Because the fiber system is used as secondary reinforcing, the loss of strength will not immediately jeopardize the structure, however the lack of higher temperature data results in uncertainty regarding what repairs are required if the material is exposed to fire, steam leaks, or other elevated temperature effects. No published data show what level of heat exposure requires replacement of the external reinforcing. The effectiveness of the available fire proofing systems also needs further investigation. Perhaps areas exposed to direct flame need replacement but areas further away that were subjected to elevated but lower temperatures will not. A pilot study was conducted to explore these questions and evaluate the feasibility of a larger scale study. The results of the pilot study are provided below.

\section{EXPERIMENTAL PLAN}

The pilot study consisted of compression tests on eight series of 200-mm diameter by $400-\mathrm{mm}$ high externally reinforced concrete cylinders. All of the specimens were cast from a single batch of concrete and cured under identical conditions. A moderate strength concrete mix was used with a compressive strength of approximately $40 \mathrm{MPa}$. The concrete mix is shown in Table 1 . The cylinders were cured at $22^{\circ} \mathrm{C}$ and $98 \%$ humidity until three days prior to wrapping. At that time they were allowed to air dry.

The cylinders were reinforced in the hoop direction with two continuous layers of a reinforcing fabric applied with a two-part epoxy. The fabric primarily consisted of glass fibers running in the hoop direction. The primary glass fibers were woven around bundles of aramid and glass fibers running in the cross direction. The aramid fibers added in the cross direction

Table 1. Concrete mix proportions $\left(\mathrm{kg} / \mathrm{m}^{3}\right)$.

\begin{tabular}{lc}
\hline Material & Weight $\mathbf{( k g / \mathbf { m } ^ { \mathbf { 3 } } )}$ \\
\hline Type 1 cement & 360 \\
$20 \mathrm{~mm}$ crushed limestone & 570 \\
$10 \mathrm{~mm}$ crushed limestone & 570 \\
Sand (fineness 2.0) & 657 \\
Water & 198 \\
\hline
\end{tabular}


improve handle ability of the saturated composite. The seam was wrapped an addition 50-mm beyond the completion of the second layer. The system is very similar to a commonly used commercial composite system [17-19] but with a modified solvent-free two-component epoxy for higher temperature applications. Two sets of cylinders were treated with an epoxy based fireproofing coating and paint. The same technician following the manufacturer's recommendations applied all reinforcement and protective coatings. Typical properties of the composite are provided in Table 2.

Sets of four cylinders were then heated for $90 \mathrm{~min}$ in an electric oven to temperatures up to $185^{\circ} \mathrm{C}$. Oven temperatures were monitored closely because of an initial temperature drop that occurs when the mass of concrete is introduced to the oven. Direct exposure to flame was not considered because it was known that this would simply burn off the epoxy resin. Preliminary tests with coupons of the composite indicated the particular system under consideration would degrade well below $300^{\circ} \mathrm{C}$.

The cylinders were allowed to cool to ambient temperature, were capped, and then tested in compression to failure. Because composite wrap systems

Table 2. Typical composite properties $[17,18,22]$.

\begin{tabular}{|c|c|c|}
\hline Property & $\begin{array}{l}\text { ASTM } \\
\text { Method }\end{array}$ & $\begin{array}{l}\text { Typical } \\
\text { Test Value }\end{array}$ \\
\hline \multicolumn{3}{|l|}{ Primary E-glass fiber [17] } \\
\hline Tensile strength & D-2343 & 2068.3 MPa \\
\hline Elongation at break & D-2343 & $3.2 \%$ \\
\hline Tensile modulus & D-2343 & $72.4 \mathrm{GPa}$ \\
\hline \multicolumn{3}{|l|}{ Polyaramide fiber [17] } \\
\hline Tensile strength & D-2343 & $2757.8 \mathrm{MPa}$ \\
\hline Elongation at break & D-2343 & $2.2 \%$ \\
\hline Tensile modulus & D-2343 & $124.8 \mathrm{GPa}$ \\
\hline \multicolumn{3}{|l|}{ Epoxy resin [22] } \\
\hline Glass transition temperature & & $121^{\circ} \mathrm{C}$ \\
\hline Tensile strength & D-638 & $50.7 \mathrm{MPa}$ \\
\hline Tensile modulus & & $2.23 \mathrm{GPa}$ \\
\hline Elongation percent & D-638 & $3.5 \%$ \\
\hline \multicolumn{3}{|l|}{ Composite laminate* $[18]$} \\
\hline $\begin{array}{l}\text { Ultimate tensile strength in } \\
\text { primary direction }\end{array}$ & D-3039 & $575 \mathrm{MPa}$ \\
\hline Elongation at break ( $\mathrm{min}$ ) & D-3039 & $2.2 \%$ \\
\hline Tensile modulus & D-3039 & $26.1 \mathrm{GPa}$ \\
\hline \multicolumn{3}{|l|}{ Ultimate tensile strength $90^{\circ}$} \\
\hline to primary fiber & D-3039 & $34.5 \mathrm{MPa}$ \\
\hline Laminate thickness & & $1.3 \mathrm{~mm}$ \\
\hline
\end{tabular}


are often used as secondary reinforcement for extreme or infrequent load events, there is a low probability of elevated temperatures occurring simultaneously with an extreme loading event unless the event caused the elevated temperatures. Therefore, this study focused on whether the composite reinforcing system is still effective as secondary reinforcing after cooling and what affect the heat treatment has on the mechanism of failure. Heating and testing of cylinders did not occur until the concrete had aged six weeks. The cylinders were tested the day after they were heated and all testing was completed over a four-week period. Loading was performed using a hydraulic testing machine under load rate control. The test program and the test results are summarized in Table 3.

\section{RESULTS AND DISCUSSION}

The results of the 31 cylinder tests included in the pilot study are plotted in Figure 1; while the data are shown in Table 3. The ratio of the average group failure stress to the average of the unheated wrapped control group is noted in the table. The failure modes recorded in the table are consistent with previous observations of Karbhari and Howie [5]. Failure modes observed in this study include fiber dominated modes such as localized fiber rupture, vertical splits, and angled splits and resin dominated modes such as seam debonding and hoop split. These failure modes are shown in Figure 2. Figure 3 shows photographs of typical failures in this study.

Local fiber rupture is characterized by fracture of the hoop direction fibers in a localized area accompanied by a bulging of crushed concrete behind the composite. Vertical splits and angled splits are also fiber rupture phenomena however the fiber failure propagates over a greater distance. Hoop split is characterized by horizontal splitting of the wrap between bundles of primary hoop direction fiber. This breaks the reinforcing wrap into a structure of bands rather than a continuous sheet. Failure occurs when an isolated band then ruptures. Seam debonding is characterized by separation between the two layers of wrap. The separation starts at the seam and continues as a shear failure between the layers. This effectively cuts the confining capability in half, leading to specimen failure.

Both fiber dominated and resin dominated failure modes were observed in the unheated control group. Two specimens failed due to localized rupture of the fibers in the hoop direction and two specimens failed with a hoop split. Inspection of the failed specimens revealed that good bond remained between the composite and the concrete. The results show the FRP reinforcing system increased the compressive strength of the concrete cylinders by approximately $255 \%$. This result is consistent with the manufacturer's design criteria [19] which predicted an increase of $222 \%$. 
Table 3. Test results from the pilot study of heat effects on composite external reinforcement.

\begin{tabular}{|c|c|c|c|c|c|c|c|}
\hline $\begin{array}{l}\text { Cylinder } \\
\text { Number }\end{array}$ & Wrap & $\begin{array}{c}\text { Fire } \\
\text { Protection }\end{array}$ & $\begin{array}{l}\text { Temp. } \\
\text { ( } \mathrm{C})\end{array}$ & $\begin{array}{c}\text { Failure } \\
\text { Mode }\end{array}$ & $\begin{array}{l}\text { Ultimate } \\
\text { Stress } \\
\text { (MPa) }\end{array}$ & $\begin{array}{c}\text { Group } \\
\text { Ave. }\end{array}$ & $\begin{array}{c}\text { Ratio vs. } \\
\text { Wrapped at } \\
\text { Ambient } \\
\text { Temp. }\end{array}$ \\
\hline 1 & $\mathrm{~N}$ & $\mathrm{~N}$ & 21 & - & 42.23 & & \\
\hline 2 & $\mathrm{~N}$ & $\mathrm{~N}$ & 21 & - & 38.89 & 39.93 & 0.38 \\
\hline 3 & $\mathrm{~N}$ & $\mathrm{~N}$ & 21 & - & 38.66 & & \\
\hline 4 & $Y$ & $\mathrm{~N}$ & 21 & LFR & 96.99 & & \\
\hline 5 & $Y$ & $\mathrm{~N}$ & 21 & LFR & 106.33 & & \\
\hline 6 & $Y$ & $\mathrm{~N}$ & 21 & $\mathrm{HS}$ & 102.29 & 104.31 & - \\
\hline 7 & $Y$ & $\mathrm{~N}$ & 21 & $\mathrm{HS}$ & 111.64 & & \\
\hline 8 & $Y$ & $\mathrm{~N}$ & 120 & SD & 107.57 & & \\
\hline 9 & $Y$ & $\mathrm{~N}$ & 120 & LFR & 90.51 & & \\
\hline 10 & $Y$ & $\mathrm{~N}$ & 120 & HS & 103.3 & 102.30 & 0.98 \\
\hline 11 & $Y$ & $\mathrm{~N}$ & 120 & HS & 107.84 & & \\
\hline 12 & $\mathrm{Y}$ & $\mathrm{N}$ & 135 & HS & 105.42 & & \\
\hline 13 & $Y$ & $\mathrm{~N}$ & 135 & SD & 101.50 & & \\
\hline 14 & $Y$ & $\mathrm{~N}$ & 135 & $\mathrm{HS}$ & 95.87 & 100.24 & 0.96 \\
\hline 15 & $Y$ & $\mathrm{~N}$ & 135 & HS & 98.17 & & \\
\hline 16 & $Y$ & $\mathrm{~N}$ & 150 & SD & 91.83 & & \\
\hline 17 & $\mathrm{Y}$ & $\mathrm{N}$ & 150 & LFR & 84.73 & & \\
\hline 18 & $Y$ & $\mathrm{~N}$ & 150 & SD & 91.98 & 91.13 & 0.87 \\
\hline 19 & $Y$ & $\mathrm{~N}$ & 150 & AS & 95.97 & & \\
\hline 20 & $\mathrm{Y}$ & $\mathrm{N}$ & 180 & SD & 85.49 & & \\
\hline 21 & $Y$ & $\mathrm{~N}$ & 180 & SD & 88.12 & & \\
\hline 22 & $Y$ & $\mathrm{~N}$ & 180 & SD & 81.34 & 85.19 & 0.82 \\
\hline 23 & $Y$ & $\mathrm{~N}$ & 180 & SD & 85.79 & & \\
\hline 24 & $\mathrm{Y}$ & $Y$ & 150 & LFR & 102.48 & & \\
\hline 25 & Y & Y & 150 & HS & 109.97 & & \\
\hline 26 & $Y$ & Y & 150 & LFR & 95.83 & 101.13 & 0.97 \\
\hline 27 & $\mathrm{Y}$ & $Y$ & 150 & VS & 96.23 & & \\
\hline 28 & $Y$ & $Y$ & 185 & $\mathrm{HS}$ & 96.32 & & \\
\hline 29 & $\mathrm{Y}$ & $Y$ & 185 & LFR & 85.82 & & \\
\hline 30 & $Y$ & Y & 185 & $\mathrm{HS}$ & 93.48 & 93.5 & 0.90 \\
\hline 31 & $\mathrm{Y}$ & Y & 185 & HS & 98.36 & & \\
\hline
\end{tabular}
Debond.

This consistency provided a strong indication the wrap application and testing methods was satisfactory. As expected for the tested wrap architecture, the strengthening mechanism can be directly related to the confining stress provided by the composite reinforcing [5]. 


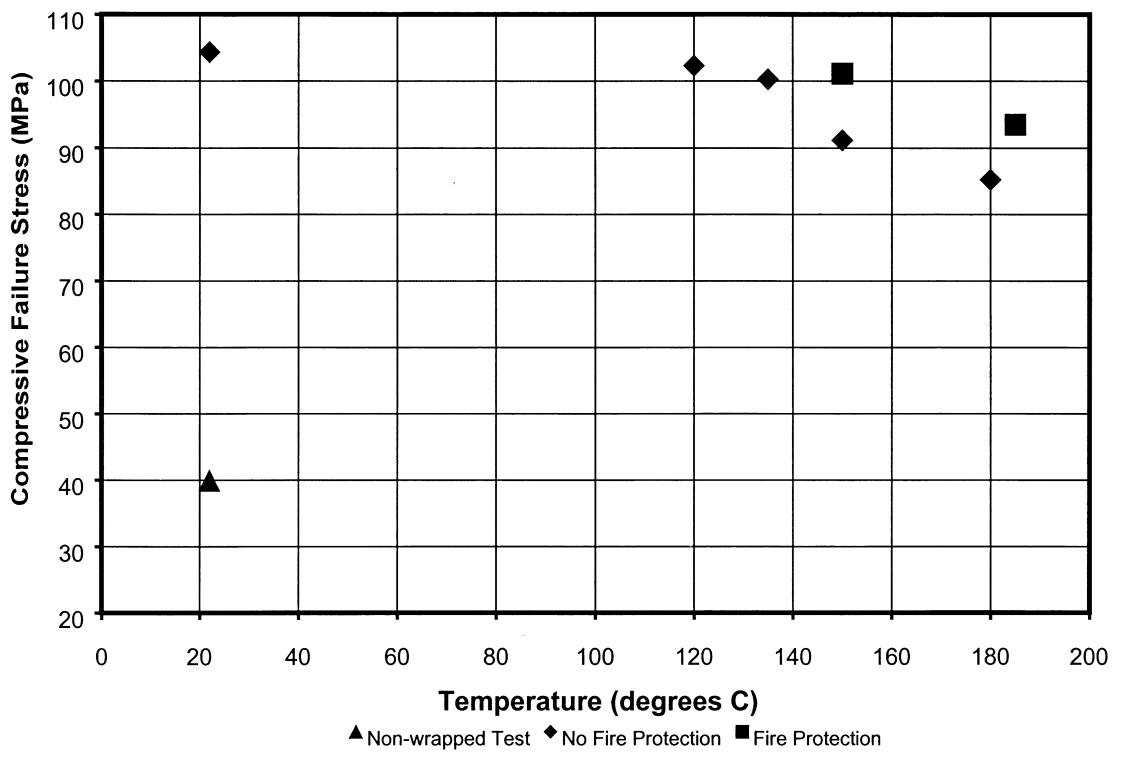

Figure 1. Results of thermal studies of an external reinforcing system.

Resin Dominated
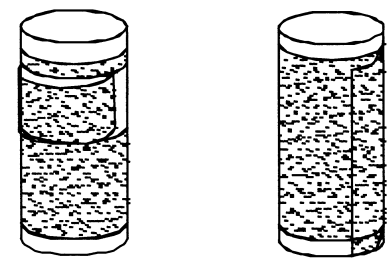

Hoop Spllts

Seam Debond

\section{Fiber Dominated}
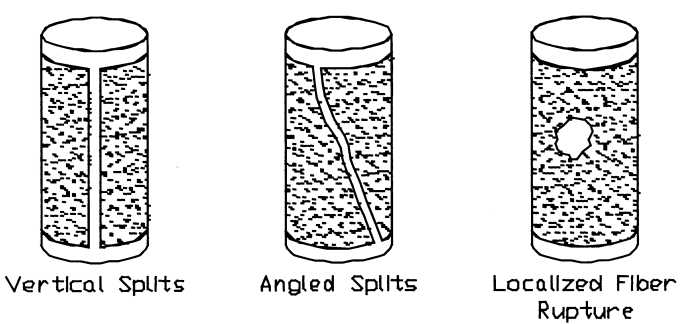

Figure 2. Examples of cylinder failure modes (adapted from Karbhari and Howie, 1997 [5]). 


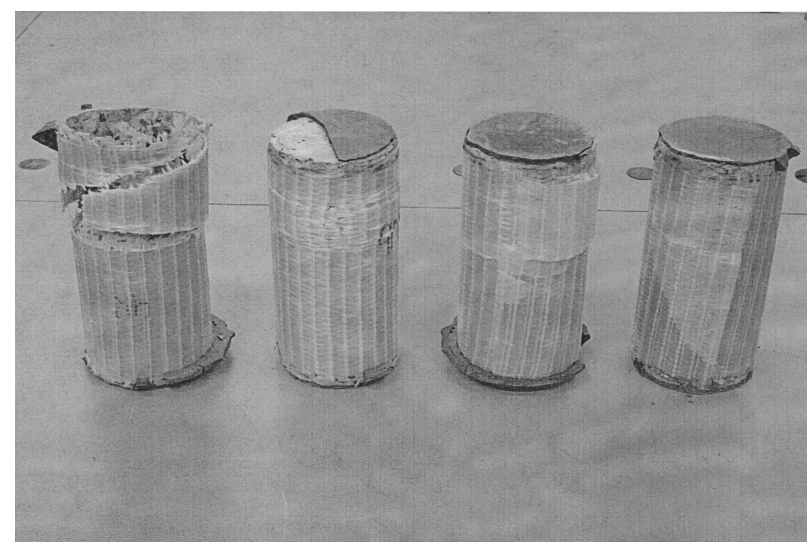

Figure 3. Typical cylinder failures. From left: angled split, local fiber rupture, hoop split, seam debond.

After $90 \mathrm{~min}$ heat exposures up to $135^{\circ} \mathrm{C}$, the cylinders showed no significant loss of strength. The maximum loss over this range was $4 \%$ (less than statistical significance) at $135^{\circ} \mathrm{C}$. Above $135^{\circ} \mathrm{C}$ there was a continuous decrease in compressive strength as the heat exposure increased. At $150^{\circ} \mathrm{C}$ the decrease was $13 \%$ and at $180^{\circ} \mathrm{C}$ it was $18 \%$. As indicated in Table 3, the mode of failure varied. However, resin failures dominated; only three of the sixteen failures of heated specimens were classified as fiber dominated modes. As the temperature increased, the trend in the type of resin failure was a change from hoop split to seam debonding. The resin failures between wrap layers appeared to initiate at the end seam of the wrap.

Strain measurements made by Karbhari and Howie [5] on specimens with wrap architecture of fibers predominantly in the hoop direction only show significantly higher hoop strains near midheight than toward the ends of the cylinder. This differential in the hoop strains results in a shear strain through the thickness of the resin. When the shear strain exceeds the shear capacity of the resin, the wrap begins to break into bands, reducing the load carrying capacity. This was a common mode of failure for the control specimens and those heated to temperatures through $135^{\circ} \mathrm{C}$. Above $135^{\circ} \mathrm{C}$ seam debonding became more prevalent.

The thermal behavior of epoxy resin systems is complex. Slightly elevated temperature $\left(\sim 60^{\circ} \mathrm{C}\right)$ typically accelerates the reaction rate associated with the curing of the epoxy. However, as the temperature nears the glass transition temperature $\left(T_{g}\right)$ of the epoxy, the resin begins to lose its glassy character and gradually becomes more rubbery. However, it is important to recognize that the glass transition temperature does not imply a sudden shift 


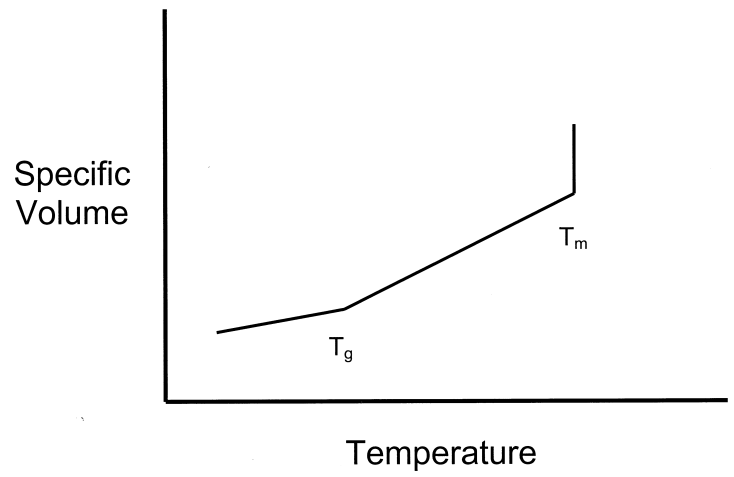

Figure 4. Specific volume versus temperature plot for a partially crystalline polymer (adapted from Flory and Hall, 1951 [23]).

from a non-deformable solid to a suddenly malleable material. Instead, $T_{g}$ represents the inflection point on a specific volume-versus temperature curve, as shown in Figure 4. This second order thermodynamic transition merely indicates the onset of segmental mobility [20]. Even at temperatures above $T_{g}$, the degree of segmental mobility remains highly dependent on chain stiffness and intermolecular forces [21].

At some temperature greater than $T_{g}$, the stresses associated with the differential thermal expansions of the concrete and epoxy become sufficient to disrupt the bonding between the fiber wrap and epoxy. Upon cooling, the epoxy reverts to its glassy state, but the irreversible disruption of the bonding leaves a weak point that will cause premature failure when exposed to a shear stress.

The glass transition temperature of the epoxy used in this study was $121^{\circ} \mathrm{C}$. Even at a temperature of $135^{\circ} \mathrm{C}$, only a $4 \%$ loss of strength was observed. This loss was not statistically significant. By contrast, cylinders heated to $150^{\circ} \mathrm{C}$ showed a $13 \%$ reduction in strength and seam debonding replaced hoop split as the predominant mechanism of failure. This result would seem to indicate that a heat-protection system does not need to keep the internal temperature below the glass transition temperature of the epoxy, as exceeding the glass transition temperature showed no significant impact on either strength or failure mode.

The results from the two series tested with a fireproofing application are shown in Figure 5 (an enlargement of an area of Figure 1). At $150^{\circ} \mathrm{C}$, three of the four failures were fiber-dominated modes and the cylinders retained $97 \%$ of the strength of those wrapped and not heated. At $185^{\circ} \mathrm{C}$, three of four failures were resin-dominated hoop splits and the cylinders retained $90 \%$ of the strength of those wrapped and not heated. These tests indicate 


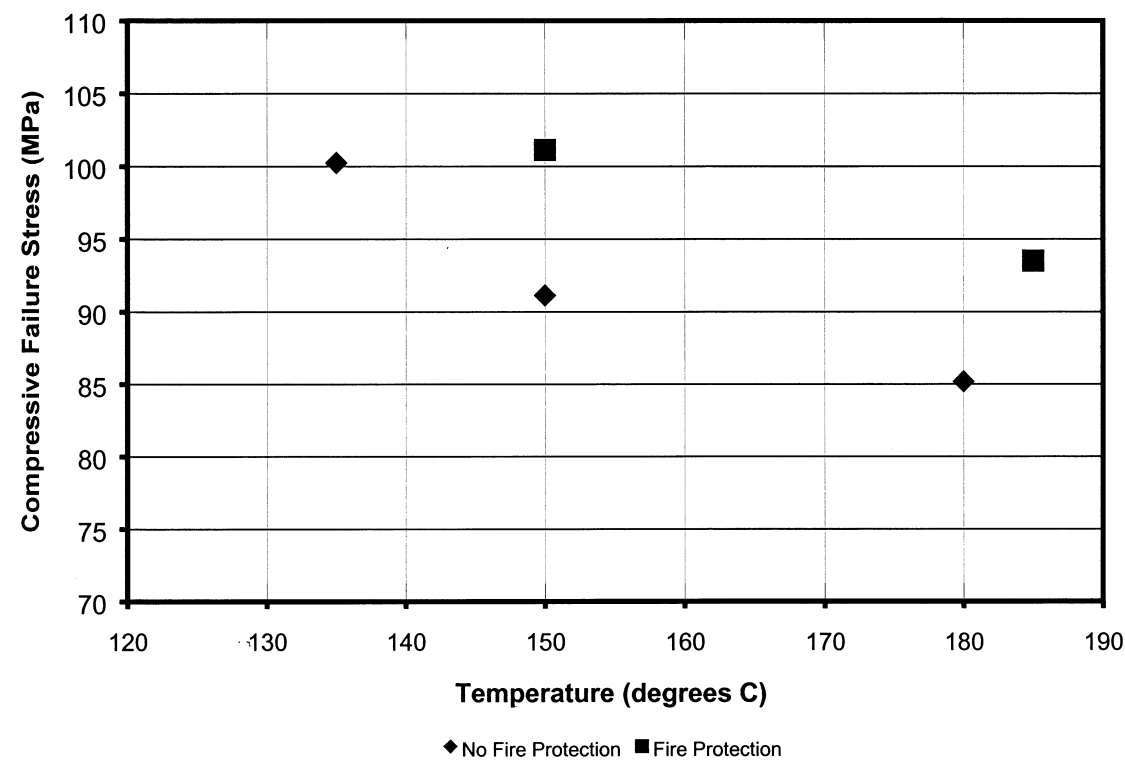

Figure 5. Comparison of test results with and without fire protection at similar temperatures.

the fire proofing system may have reduced internal temperatures approximately $30^{\circ} \mathrm{C}$ under a 90 -min exposure condition.

\section{SUMMARY AND CONCLUSIONS}

Compression testing of externally reinforced concrete cylinders after exposure to elevated temperatures shows there is a transition temperature above which heating the composite reduces its strength. For this study the composite strength was essentially unaffected by the heat exposure up to $135^{\circ} \mathrm{C}$, significantly above the $121^{\circ} \mathrm{C}$ glass transition temperature of the epoxy. At higher temperatures, there was a steady decline in the ability of the composite to strengthen the concrete cylinders. The fire protection coating tested was effective in reducing the degradation due to heating. The system appeared to have reduced the internal temperatures during heating of the cylinders as indicated by an upward shift in the exposure temperature that resulted in loss of strength.

It was also found that the mode of failure of the composite reinforcing system changed as exposure temperature increased. At the lower temperatures in the study, shear failures through the thickness of the epoxy resin segregated the composite into bands. This decreased the ability of the composite to confine the concrete. Failure was ultimately due to rupture 
in the hoop direction of a segregated band. At higher temperatures the composite reinforcement tended to fail as a shear failure in the resin between layers of wrap. This work implies that the glass transition temperature may not be the critical point that heat protection systems must enable the composite to remain below during short term exposure conditions. Rather, it appears that the integrity of the composite system would be maintained for as much as $30^{\circ} \mathrm{C}$ above the glass transition temperature.

\section{ACKNOWLEDGMENTS}

The authors would like to express their appreciation to Mr. Peter Milligan of Fyfe, Co who provided advice and material donations for this project. Emily Stidworthy, Claire Bracher, and Joseph Switzer, all undergraduate students at Rowan University, also assisted in testing of the specimens.

\section{REFERENCES}

1. Bonacci, F. and Maalej, M. (2000). ACI Structural Journal, 97(5): 703-711.

2. Nitereka, C. and Neale, K.W. (1999). Canadian Journal of Civil Engineering, 26(5): 646-654.

3. Triantafillou, T.C. (1998). ACI Structural Journal, 95(2): 107-115.

4. Khalifa, A., Gold, W.J., Nanni, A. and Adbel Aziz, M.I. (1998). Journal of Composites for Construction, 2(4): 195-202.

5. Karbhari, V.M. and Howie, I. (1997). Journal of Reinforced Plastics and Composites, 16(11): 1039-1063.

6. Wu, Z.S. and Yoshizawa, H. (1999). Journal of Reinforced Plastics and Composites, 18(12): 1131-1155.

7. ACI Committee 440. (1996). State-of-the-Art Report on Fiber Reinforced Plastic (FRP) Reinforcement for Concrete Structures. American Concrete Institute, 68p.

8. Dutta, P.K. and Morton, S. (1999). In: Proceedings, 44th International SAMPE Symposium. May 23-27. p. 1655.

9. Toutanji, H.A. and Gomez, W. (1997). Cement and Concrete Composites, 19: 351-358.

10. Karbhari, V.M. and Engineer, M. (1996). Journal of Reinforced Plastics and Composites, 15(12): 1194-1216.

11. Steckel, G.L., Hawkins, G.F. and Bauer, Jr. J.L. (1999). 44th International SAMPE Symposium, 44: 2194-2208.

12. Kshirsagar, S., Lopez-Anido, R.A. and Gupta, R.K. (2000). ACI Materials Journal, 97(6): 703-712.

13. Toutanji, H. and Balaguru, P. (1998). Journal of Materials in Civil Engineering, 10(1): 52-57.

14. Toutanji, H.A. and El-Korchi, T. (1999). Journal of Composites for Construction, 3(1): 35-45.

15. Gentry, T.R., Bank, L.C., Barkatt, A. and Prian, L. (1998). Journal of Composites Technology and Research, 20(1): 38-50.

16. Hancox, N.L. (1998). Materials and Design, 19(3): 93-97.

17. http://rjwatson.com/tyfofaq.htm. Bridge and Structural Engineered Systems. R.J. Watson, Inc., East Amherst, NY, viewed January 9, 2001. 
18. Fyfe Co. (2000). Tyfo ${ }^{\circledR} S H E-51$ Composite Using Tyfo ${ }^{\circledR}$ S Epoxy. Materials technical data sheet. San Diego, CA: LLC.

19. R.J. Watson, Inc. (1998). Tyfo ${ }^{\circledR}$ Fiberwrap System Design Manual. East Amherst, NY. February. 31p.

20. Gibbs, J.H. and DiMarzio, E.A. (1959). Journal of Polymer Science, 40: 121.

21. Rodriguez, F. (1996). Priniciples of Polymer Systems. 4th edn. Washington D.C.: Taylor and Francis.

22. Fyfe Co., LLC. (2001). Tyfo ${ }^{\circledR}$ T High Temperature Epoxy. Materials technical data sheet (draft), San Diego, CA.

23. Flory, P.J. and Hall, H.K. (1951). Journal of the American Chemical Society, 28: 2532.

\section{BIOGRAPHIES}

\section{Douglas B. Cleary}

Douglas B. Cleary, Ph.D., P.E. is an Associate Professor in Civil and Environmental Engineering at Rowan University. He received his Ph.D., MSCE, and BSCE from Purdue University in 1992, 1988, and 1987 respectively. $\mathrm{He}$ is a member of ACI Committee 802 - Teaching Methods and Educational Materials and an Associate Member of ACI Committee 408 - Bond and Development of Reinforcement. He joined the faculty of Rowan University in 1998 following four years with Black \& Veatch.

\section{James A. Newell}

James A. Newell, Ph.D. is an Associate Professor in Chemical Engineering at Rowan University. He received his Ph.D. in Chemical Engineering from Clemson University in 1994, his M.S. from Penn State in 1990, and his B.S. from Carnegie-Mellon in 1988. He has received the Dow Outstanding New Faculty Award, The Ray Fahien Award from ASEE for contributions to engineering education, The Stanislaw Mrozowski Award from the American Carbon Society, and currently serves as Secretarytreasurer of the Chemical Engineering Division of the American Society for Engineering Education.

\section{Christopher D. Cassino}

Christopher D. Cassino earned his B.S. in Civil Engineering from Rowan University in May 2000. Currently, he is a graduate student in the Engineering Mechanics Department at Virginia Tech in Blacksburg, Virginia. Mr. Cassino is a member of ASCE Special Committee on 
Fire Protection and his current research involves developing a health monitoring system for fiber reinforced composites in infrastructure.

\section{Bradley W. Tyres}

Bradley W. Tyres is a Graduate Student in Chemical Engineering at Rowan University. He received is B.S. in Chemical Engineering in 2000. He has a strong interest in materials science and polymer research.

\section{Rosie Tortorice}

Rosie Tortorice is a sophomore Civil and Environmental Engineering student at Rowan University. She plans to graduate with a Bachelor of Science in CEE in 2003. 